\title{
Design and Implementation of a Persian-Chinese Online Dictionary Based on WAMP
}

\author{
Wei $\mathrm{Li}^{1, \mathrm{a}}$ and Liming Zhang ${ }^{1, \mathrm{~b}}$ \\ ${ }^{1}$ Luoyang University of Foreign Languages 471003 Luoyang, Henan, China \\ aw_waiyuan@163.com, bzhlm1967@sina.com
}

Keywords: Online dictionary; WAMP; Persian; Chinese

\begin{abstract}
According to the actual demand, there are more and more Persian learners in China. However, there doesn't exist a Persian-Chinese online dictionary of comprehensive and rich explanations so far. This paper designs and implements an online dictionary based on WAMP, which can look up words, phrases and sentences together with rich examples between Persian and Chinese, aiming at bringing a convenience to Persian learners.
\end{abstract}

\section{Introduction}

Dictionaries are very necessary for people of different mother tongues to communicate with each other. They can obtain the meanings and usages of a word by means of dictionaries. With the rapid development of computer science and network technology, electronic dictionaries and online dictionaries have gradually come into people's life, which can bring more convenience than paper dictionaries. As for online dictionaries, they have the advantages of easy operation, speedy, good dynamics, quick updating, etc, which have become most network users' main approach of obtaining meanings of words in the process of learning languages, translating, retrieving information, etc [1]. Presently, online translations such as Google, Baidu, Youdao and the like are well-known and useful which all contain many kinds of languages. However, Persian and Chinese online translations are still in the early stages and few online dictionaries between Persian and Chinese can be available through the Internet search. Take Google translation for example, although users can look up words between Persian and Chinese by it, yet there is not phonetic symbols or examples with translations.

China and Iran are important Asian countries and bilateral relations have always been friendly. The two countries' economic structures are highly complementary and cooperation space is of high potential. Since ancient times, Iran has been the important transport hub and trade center of the Silk Road. As Iran is situated in a very strategic geographical location, Iran will play an irreplaceable role in the cooperation construction of both the maritime and overland Silk Roads in the future. Nowadays, there are more and more Persian learners in China and some universities have offered the major of Persian one after another. However, in contrast to majority languages, Persian learning resources are relatively limited, especially in the dictionary field. Therefore, this paper aims to construct an online Persian and Chinese dictionary of rich vocabulary and examples for Persian learners.

\section{Related Work}

With the rapid development of network technology, the research of the online dictionary has been into the mature period, which has brought a great convenience to people. Some researchers have applied Windows 2000 Server and SQL Server 2000 to construct an online dictionary of Pandita Tibetan, Chinese and English [2]. Several researchers have put forward useful information for establishing a user-friendly Arabic electronic dictionary by asking Arabic teachers and three computer experts to fill evaluation forms [3]. A scholar has discussed the characteristics of the online dictionary and forecasted its development trend [4]. Another scholar has designed and implemented an online dictionary software for the Internet language by applying .NET technology, which can help users find matched Internet language explanations by means of inputting the key words [5]. Also, a related paper has 
illustrated the necessity of establishing Minnan dialect online dictionary and discussed deeply building steps of the online dictionary from seven aspects of user need, management platform, data acquisition specification, selection of data source, data collection, information organization and service function and then took the online dictionary as an example to analyze the main characters of library information service [6]. Another related paper holds the view that Wiki is another new Internet application after the blog and has put forward a method of establishing dynamic Wiki websites based on WAMP [7]. As for online Persian dictionaries, there is Farsidic [8], Babylon [9], etc, but all of them don't have the function of translating words between Persian and Chinese.

\section{Functions and Features}

This online dictionary contains five parts: the Persian to Chinese dictionary, the Chinese to Persian dictionary, the sentence dictionary, free online resources and a message board. All the dictionaries support fuzzy inquiry, by which users can input words, phrases or sentences to find related explanations, examples and idioms conveniently. Both the Persian to Chinese dictionary and Chinese to Persian dictionary contain phonetic symbols, phrases and examples, via which users can know a word's usage deeply. The sentence dictionary can help users learn how to make a sentence with a word. The section of free online resources provides useful Persian materials for users to download. As for the message board, users can write any suggestion and comment for the online dictionary's continuous improvement.

The online dictionary has the following features:

1. Short renew cycle

We will collect new words and phrases by semi-automatic or automatic ways with manual validation constantly and the message board is also a good platform for us to learn good advice.

2. Light and free of installation

This feature belongs to all online dictionaries. That is to say, the dictionary doesn't occupy space of computer hard disk and as long as there is a browser in the client, users can use the dictionary.

3. Data security

As the database is on the server and not directly manipulated by users, the dictionary data are relatively safe and hardly need maintenance.

\section{Design and Implementation}

This online dictionary is developed on the platform of WAMP 2.5 [10], which consists of Apache, MySQL and PHP. As a most popular server software, Apache is not only free, but also continuously improved by people. Therefore, it serves as the proxy server of the online dictionary. MySQL is a well-known relational database management system, which is of a small size, fast and low-cost. Small and medium-size websites usually apply MySQL as the database. The scripting language of PHP is usually used on the web server, which can create web pages. Besides, PHP can be used on most servers and operating systems.

Establishment of the Dictionary Database. The dictionary database should be constructed first and phpMyAdmin will be used to add, edit and delete data. First, a database should be established with the name "dictionary" and collation "utf8_general_ci". Then, three tables with the names of "t_dic1", "t_dic2" and "t_line" should be established, which will store the Persian to Chinese dictionary, the Chinese to Persian one and the sentence dictionary respectively. Next, Excel 2010 will be applied to import data with the main sql code:

="insert into t_dic (PERSIAN, CHINESE) values ('"\&A1\&"',"'\&B1\&"');"

An example of the tables is shown in Fig. 1, 


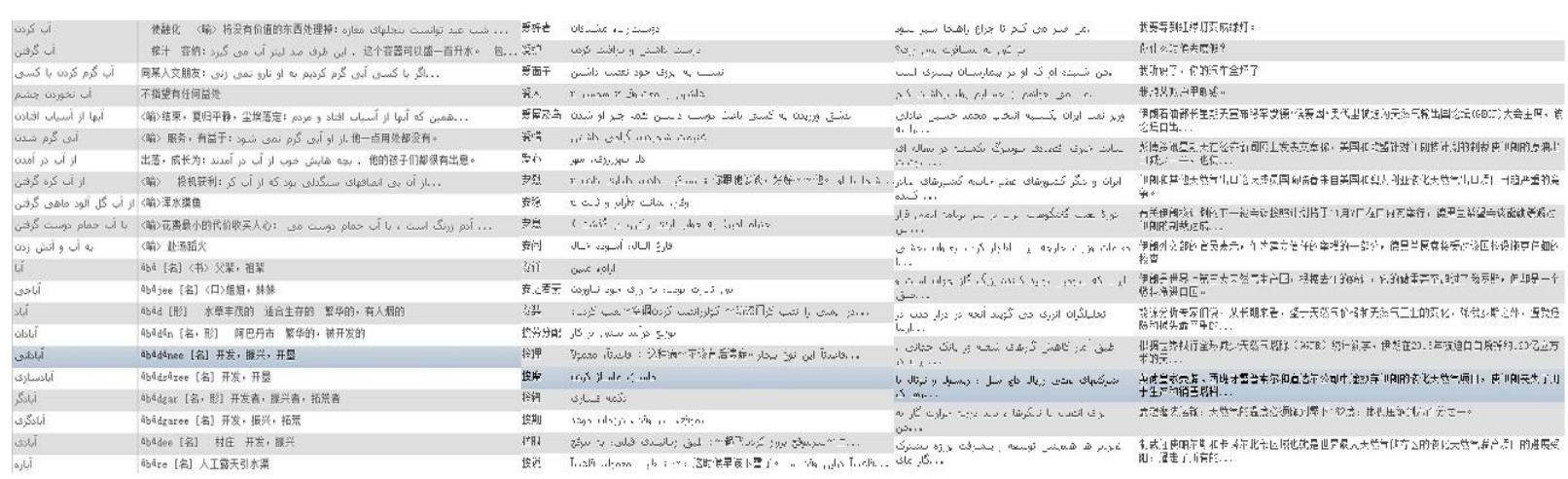

Figure 1. Part of the online dictionary database

Design of Web Pages. This online dictionary consists of six pages: Home, Persian-Chinese dic, Chinese-Persian dic, Sentence dic, Resources and Message board. Take Persian-Chinese dic for example, as is shown in Fig. 2,
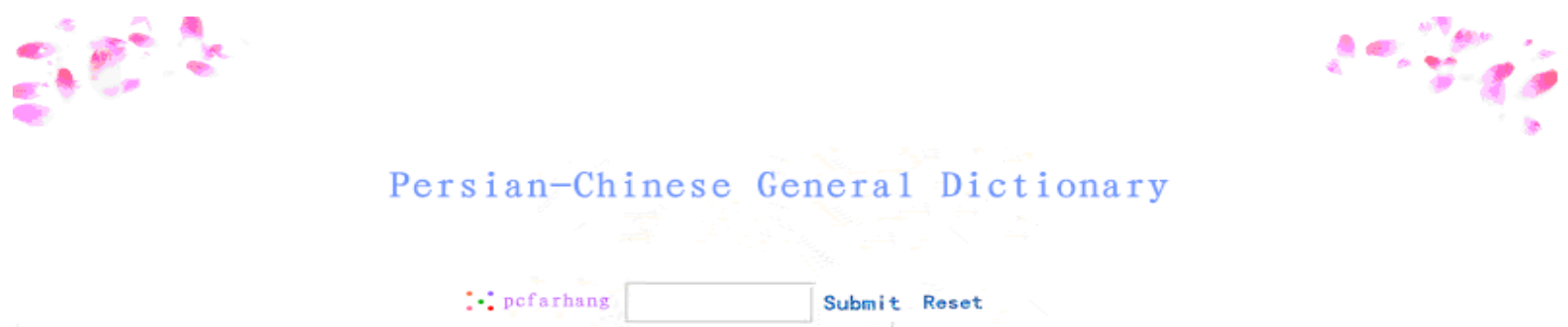

Figure 2. Persian-Chinese dic page

The core php code of the query page is as follows:

\$word = \$_POST ['word'];

\$mysqli = new mysqli('localhost','root',",'dictionary');

if(!\$mysqli)

\{

echo "ERROR:".mysqli_connect_error();

exit;

\}

\$mysqli->set_charset("utf8");

$\$$ sql = "select * from $t \_$dic where PERSIAN like '\%".\$word."\%"';

\$result=\$mysqli-> query $(\$ s q 1)$;

while $($ (\$row $=$ \$result->fetch_assoc ()$) !=$ null $)\{$

echo '<p style="font-size:30px; color:dark" >';

echo \$row['PERSIAN'].'<br/>'s Chinese meaning is: <br/>'.\$row['CHINESE'].'<br/>';

echo ' $</ \mathrm{p}\rangle\langle\langle\mathrm{hr} /\rangle$ ';

\}

Echo ' $<$ input type = "button" value = "back" style = "position: fixed; top: 500px; left: 1200px; font-size: 40px; color: green; width: 100px; height: 60px" onclick = javascript: window. location. Href = "// localhost/BHinput. php" >';

?> 


\section{Conclusion}

This paper has discussed the design of a Persian-Chinese online dictionary and also released the core source code. Presently, the system has been put to use in the campus network and also received a lot of acclaim. Next, we will consider putting it in the Internet. Before that, there are still some aspects for improvement.

1. In order to meet the needs of people of more professions, the online dictionary will set up terminological dictionaries, such as financial glossary, architecture dictionary, etc.

2. The online dictionaries now contain phonetics. Next, human voice should be added so as to provide a convenience to Persian learners.

\section{References}

[1] Song, P. Y. \& Liu, N. J., Chinese-English and English-Chinese Online Didtionary. Journal of Qingdao Hotel Management College, 1(2), pp. 38-41, 2009. (In Chinese)

[2] Cai, Z. T. \& Li, M. C., Design of the Networked Edition-Banzhida Tibetan-Chinese-English Electronic Dictionary. Computer Engineering and Applications, 41(17), pp. 126-128, 2005. (In Chinese)

[3] Che Abdul, M. \& Hassan, B., The Development of E-dictionary for the Use with Maharah Al-qiraah Textbook at a Matriculation Center in a University in Malaysia. The Turkish Online Journal of Education Technology, 10(3), pp. 255-264, 2011.

[4] He, C. M., Talking about the Online Dictionary. Sci-Tech Information Development \& Economy, 21(19), pp. 55-57, 2011. (In Chinese)

[5] Ye, X. H., Design and Realization of .NET-based Online Dictionary Software for Internet Language. Computer Age, (9), pp. 27-29, 2010. (In Chinese)

[6] Tong, G. L., Library Characteristic Information Service for National Research Platform-a Case Study of Establishment of Minnan Dialect Online Dictionary. Hebei Sci-Tech Library Journal, 28(1), pp. 66-72, 2015. (In Chinese)

[7] Zhang, R., Gao, L. \& Wang, C. B., A Method of establishing Dynamic Wiki Website Based on WAMP. Neijiang Ke Ji, (4), pp. 139-141, 2008. (In Chinese)

[8] Available at: http://farsidic.com/en/Lang/EnFa

[9] Available at: http://translation.babylon-software.com/english/to-persian/

[10] Available at: http://www.xiazaiba.com/html/27954.html 